\title{
CONCEPTUAL SCHEME FOR ENSURING THE ENERGY EFFICIENCY PRINCIPLE IN MODERN CONTAINER FLEET
}

\author{
Andriy Lysyy \\ Department of Navigation and handling ship \\ Azov Maritime Institute of National University "Odessa Maritime Academy" \\ 19 Chernomorskaya str., Mariupol, Ukraine, 87517 \\ anlis@ami.edu.ua \\ Vitaliy Kotenko \\ Department of Navigation and handling ship \\ National University "Odessa Maritime Academy" \\ 8 Didrikhson str., Odessa, Ukraine, 65029 \\ dogyua@gmail.com \\ Stanislav Yakovtsev \\ Department of Navigation and handling ship \\ National University "Odessa Maritime Academy" \\ 8 Didrikhson str., Odessa, Ukraine, 65029 \\ stanislavyakovtsev@gmail.com
}

\begin{abstract}
As a result of the analysis of the modern merchant fleet, indicators have been revealed of an increase in the size of modern merchant vessels, which affects the overall energy efficiency. It should be noted a significant increase in the container fleet, namely, not only an increase in the number of vessels themselves, but also an increase in the average carrying capacity by almost 2.8 times. As a result, emissions to the atmosphere have also increased due to a significant increase in ship propulsion power and fuel consumption. This is due to the specifics of container traffic, namely for the rapid transportation of goods from port A to port B, for which container ships often move in all weather conditions with maximum speed, respectively, fuel consumption is enormous compared to other types of ships.

Despite the fact that the goods must be delivered as soon as possible and without delay, in practice, due to the lack of effective feedback between all participants in the transportation process, this is not always possible. The inefficiency of feedback leads to wasteful resources, which in turn increases the financial costs of the shipowner by increasing fuel consumption. It also reduces the energy efficiency of the ship and increasing emissions of harmful substances into the atmosphere.

Considering the experience of the giants of maritime transport such as MAERSK, MSC, CMA CGM, it is possible to see that all participants in the process are single unit and interested in maximum efficiency of transportation. Containers of smaller companies that do not own their terminals often face ineffective feedback and are not able to influence the situation.

The conceptual scheme proposed in the article should increase the efficiency of feedback between the vessel charter and the port, which, in turn, will increase the efficiency of sea freight. Constant access to information about the situation in the port will make it possible to avoid unnecessary delays of the ship.
\end{abstract}

Keywords: inefficient use of resources, shipping, container fleet, feedback.

\section{Introduction}

Energy efficiency is the rational use of energy resources to support technical processes. The use of the smallest possible amount of fuel and energy resources will lead to an increase in energy efficiency with the existing development of technologies.

Energy efficiency is also an important measure to save the environment. A more rational use of fossil fuels in order to generate energy reduces emissions of harmful substances into the atmosphere. The energy that has been saved can be used instead of the newly created one, thus reducing environmental pollution. Energy saving is also very profitable from the economic side [1].

Today, the world community is aware that reducing energy consumption is an important way to minimize the negative impact on the environment. This issue is being addressed by many 
international organizations, such as IMO. From 9 to 13 April 2018, the seventy-second session of the Marine Environment Protection Committee takes place in London, at the headquarters of the International Maritime Organization (IMO). At the session, special attention is paid to the prevention of environmental pollution and the reduction of greenhouse gas emissions from ships. According to the report of the European Parliament, today the international shipping sector accounts for about $2.5-3 \%$ of global greenhouse gas emissions. If leave the process of carbon dioxide emissions unregulated, then by 2050 the volume of its emissions into the atmosphere from ships will be $17 \%[2,3]$.

Also, many companies have developed and implemented a program of energy conservation and energy efficiency, aimed at the efficient use of fuel and energy resources and improving the environmental safety of the fleet. In recent years, new systems and tools for monitoring and reporting energy efficiency have been developed and implemented, the neglect of which can lead to additional costs and fines of the shipowner. Environmental management systems are in place, built in accordance with the principles, goals and objectives of the environmental policy. The system covers the activities of employees of all structural divisions of the fleet, starting with the crews of the ships and ending with the top managers.

Energy efficiency systems should be integrated around the world in all areas related to cargo transportation by sea routes, so this important issue should be relevant not only for shipping companies and international organizations, but also for international sea trading ports as well. They should be aware of the degree of their responsibility and strive to improve the elements of transport logistics, to cooperate with operators and shipowners as efficiently as possible, as well as with ships directly through the introduction of innovations and staff development.

At the moment, there is no effective feedback scheme between all participants in the shipping process. Information provided by the port as usual is not relevant and does not reflect the current situation at the moment. This is one of the causes of ship delays and has a negative impact on energy efficiency and environmental pollution from additional emissions into the atmosphere. Identification and analysis of the problem of feedback between the port and the vessel in the container fleet, which entails a decrease in energy efficiency, increases emissions of harmful substances into the atmosphere, and also causes additional expense of the shipowner.

\section{Materials and methods of research}

Too much energy is being spent on Earth. Sources that are mostly used today are coal, oil, gas. Changes must be made to this state of affairs, and the best way to do this is to reduce energy consumption. Using less energy, let's reduce pollution.

The importance of energy efficiency and its impact on environmental pollution is becoming increasingly important and relevant in the maritime industry every year.

Despite the fact that sea shipping is recognized as the most environmentally safe compared to land and air transport, society and international organizations expect shipowners to continuously reduce pollution.

Sea transportation as a type of cargo transportation occupies the first lines in the general system of world cargo turnover. This is due to the low cost of sea delivery of large quantities of goods, which makes it a very profitable alternative to land and air transportation. Sea ships transport mainly bulk cargoes: oil, petroleum products, coal, ore, grain and others. For clarity, it can be noted that in 2015 , by sea, more than $60 \%$ of all goods of world trade in physical volume were transported, as estimated [4].

It is necessary to take into account the fact that the world fleet is growing and as of January 1, 2016 was 90,917 with an aggregate deadweight of 1.8 billion tons. The most rapid growth was observed in the gas carrier sector (by $9.7 \%$ ), as well as in the sector of container ships (7.0 \%) and other ships $(5.5 \%)$ [5].

Based on the growth trend of the global merchant fleet, the importance and relevance of energy efficiency in the shipping sector is growing. The "container revolution" in maritime transport has led to a rapid increase in shipments of so-called general cargo, finished goods and semi-finished products. Sea transportation is provided by the marine merchant fleet, the total tonnage of which 
exceeds 456 million tons. In 2015, 211 new container ships were delivered, which is less than half of the record high volume of shipments in 2008 (436 vessels). However, since the size of vessels in this market segment increased significantly, in terms of the carrying capacity of vessels in 2015, an unprecedented volume of container shipments was noted. In 2015, shipyards delivered container ships with a total capacity of 1680000 . TEUs, which is $12.7 \%$ more compared to 2014 and $12.4 \%$ compared with the previous peak level of deliveries specified in 2008. Over the past seven years, the average size of new container ships has increased by $132 \%$. In particular, the average carrying capacity of container ships has increased: for example, the average size of container ships built $15-19$ years ago is 28,516 tons of deadweight, while ships built over the past four years, an average of 2.8 times more, with an average capacity of 79,877 tons deadweight In the early 2000 s, typical bulk carriers and tankers were 2-3 times more container ships under construction, whereas at present the container fleet is ahead of other groups of ships in terms of the average size of ships [5].

Currently, the following steps to improving energy efficiency are applied in the world:

- Just in Time (JIT);

- Slow steaming.

The JIT system was developed by the Japanese company Toyota in 1954, but in practice it was widely used in maritime freight transport in the tanker fleet in 2011 by the tanker company "Fathom shipping". The principle of the system is optimization of the speed of the ship for immediate mooring to the pier without expectations and delays. If the ship did not arrive at the stated time, fines should be imposed [6-8]. In practice, this system is not always effective and may be applicable, since it is not a vessel not charter that does not have reliable information about the situation in the port and the date of the mooring to the berth is often not true. This problem is particularly acute in smaller ports.

The "Slow Steaming" approach began to be applied in 2007-2008, at the moment when the global market began to experience excess tonnage, lower freight rates, and an increase in bunker prices. Reducing average speeds has enabled many companies to cut costs and remain liquid. As it is known, the shipping market is cyclical, fuel prices have gone down, freight rates have risen. Nevertheless, this concept is still relevant in the bulk fleet [9, 10].

Based on world practice, the "slow steaming" approach most often cannot be applied to modern container fleets, so there is an urgent need to develop and introduce systems to modern shipping that would reduce inefficient fuel consumption, in turn, would reduce carbon dioxide emissions and pollution the environment. Several years ago, due to the global crisis and high oil prices, the world merchant fleet was forced to reduce the speed of ships. Now that the economy is gaining momentum and the price of oil is dropping, it is possible to see that the largest ships, namely tankers and large container ships, are beginning to accelerate again. Of course, it burns more fuel and increases the amount of harmful emissions into the environment. The total fuel consumption increased from 291 million tons to 298 million tons (+2.4 \%) from 2013 to 2015. Total $\mathrm{CO}_{2}$ emissions increased from 910 million tons to 932 million tons ( $\left.+2.4 \%\right)$ from 2013 to 2015. Of the total $\mathrm{CO}_{2}$ emissions of $55 \%$ are the following ships: container ships ( $23 \%$ ), bulk ship $(19 \%)$ and oil tankers (13\%) Fig. 1. These three classes of ships also accounted for $84 \%$ of the total shipments of shipping [11].

Therefore, the development and implementation of innovative methods of environmental protection should now be very relevant.

The biggest savings in fuel consumption are achieved by reducing the speed of the ship. Container ships sometimes reach speeds of up to 20 knots, burning a lot of expensive fuel for nothing. This can be justified if the goal is to make the ship immediately on arrival to the berth, but such high speeds and fuel consumption are inefficient and unacceptable when the ship has to wait for the berth to arrive on arrival [12]. Often this inefficient operation of the ship is associated with the lack of feedback between all participants in the process (Fig. 2). Usually the vessel will inform the charter about its position, estimated time of arrival, etc. and this charter in turn interacts with the port. But at the moment there is no effective feedback scheme between the vessel, port and the charter. 


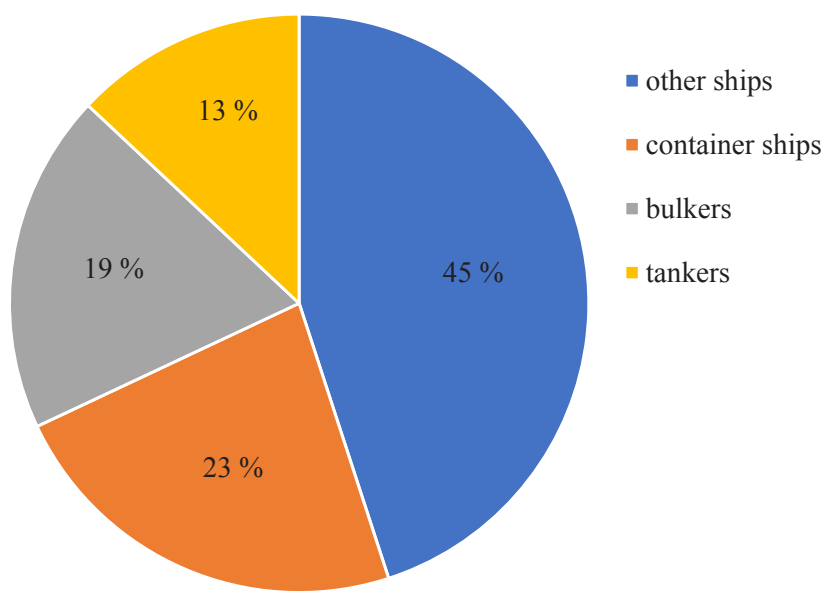

Fig. 1. $\mathrm{CO}_{2}$ emissions proportion by ship class

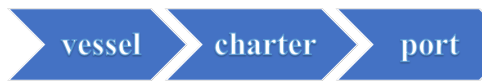

Fig. 2. Lack of feedback between the port and the ship

Today, it is possible to learn from the "big three" container shipments MAERSK, MSC, CMA CGM, which can influence the situation from the inside as they own not only ships but also entire container terminals, in other words, all participants in the process, ship, charter, port are single unit and interested in maximum efficiency. Smaller companies do not have real data on the situation in the port, because of this the relationship between the main participants of the process is broken. On this basis, the efficiency of shipping is reduced.

To solve this problem, it is possible to consider the experience of the company CMA CGM, which effectively uses the network computer program V2PS, which covers many important aspects of sea transportation. The ship every four hours reports on its location, weather conditions, estimated time of arrival, fuel consumption, etc. When the ship is in port every four hours, the ship sends a report on the productivity of the port, and the estimated time of the end of cargo operations. Based on this information, the company improves the efficiency of transportation and reduces costs. It is necessary to create and implement a conceptual scheme that could be widely applied in the field of container traffic. Information on such aspects as port loading, terminal productivity, what are the prospects of the ship staged to the pier should be available to all participants in the maritime transport. These data should be updated regularly and reflect the actual situation in the port, be freely available and analyzed by all participants in the process, namely the shipper, vessel, charter. Provided data on port performance indicators could influence the shippers decisions when choosing a port, and help improve port performance. This scheme should bring the feedback between the ship, charter, port to a fundamentally new level (Fig. 3).

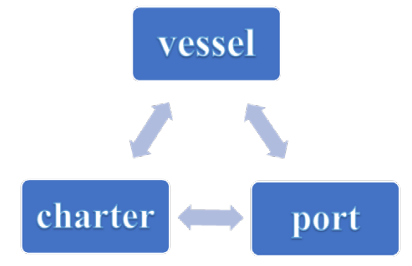

Fig. 3. Effective feedback between participants in maritime transport

It is important that the published data are real, not published only for reporting. The charter and the ship based on this information could maximize the use of its resources. In turn, the port services having real data from the charter and the ship could more effectively plan their work, avoiding unnecessary downtime of ships. 


\section{Research results}

After analyzing the modern maritime shipping market, both the stable growth of the merchant fleet in general and the container fleet segment in particular were revealed. Also, there is not only a quantitative growth of the fleet, but also an increase in the average deadweight of ships, which entails an increase in propulsion capacity and additional energy costs. All this has a negative impact on energy efficiency and an increase in the volume of emissions of harmful substances into the atmosphere. In the modern realities of container traffic, it is not always possible to apply the Slow Steaming approach, due to the need for timely and fast delivery of cargo. In this regard, the problem of inefficient use of energy resources is becoming increasingly important. Due to the lack of effective feedback, unsustainable energy costs are only increasing. Having considered the experience of the largest container carriers, it can be noted that maximum efficiency is achieved only with complete synergy of the interaction of all participants in the process. Each of the participants in the process of transportation is interested in maximum efficiency of transportation and therefore timely and relevant exchange of information plays a key role.

Creating a work program, the contents of which will be information provided by all participants in the process, is the basis of the conceptual scheme. Each of the participants in the process, namely the vessel, port and charter must provide actual and relevant information concerning the scope of their activities. The main difference from the current procedures is that the port itself provides information about the activities of the port, and it should be responsible for its accuracy and relevance. The effectiveness of the proposed scheme is possible only with the participation of all parties. Based on the relevance and reliability of information provided by one of the participants in the process, for example, at the time of the expected departure of the ship from the port, the charter and the ship can more effectively plan their future actions, avoiding unnecessary downtime and inefficient energy costs. It should be noted that the accuracy and timeliness of information in this scheme plays a key role. Neglect of the accuracy of this information is unacceptable. For example, take the common case when the date of the ship's mooring to the berth is not true. Let's consider a container ship with a cargo capacity of 4,500 TEU, which left September 1 from the Spanish port of Algeciras and is heading to the West African port of Pointe Noire. The distance of the sea passage is 3500 nautical miles. According to the information received from the charter ship, it is planned to be moored to the pier on the 7th of September. In order to arrive on time, the ship must keep an average speed of 20 nautical knots, regardless of weather conditions. At this speed, fuel consumption per day is 75 tons. Upon arrival, it turns out that the berth is occupied by another ship and mooring is planned only after 1 day. Accordingly, if the information from the port was regularly updated and reliable, the ship could proceed at a slower speed of 18 knots and at that speed the daily consumption would be 55 tons (Fig. 4). In this case, if the information that the berthing was delayed was available, the total fuel economy could be 85 tons, excluding the anchorage. In turn, it can be noted that if the charter provided the port with more accurate and timely information regarding the cargo, the delay in cargo operations could be minimized or completely avoided. This means that a ship at the berth could have completed cargo operations on time and a ship from the port of Algeciras would have avoided delay. It should be noted that timely and real information provided by the ship also plays an important role for the port and charter, making it clear whether it is realistic to arrive by the appointed date. Based on the above example, a ship delayed at the port for a day will be forced to move to its next port at a higher speed in order to deliver the cargo on time, which again will lead to additional energy costs and additional emissions of harmful substances into the atmosphere. It is necessary to emphasize once again that all this information depends on one another and must be real and regularly updated in order that in case of unforeseen problems all participants in the process can adequately and effectively respond to the situation.

In this regard, the creation of a conceptual scheme that provides more effective feedback between all participants in the process is necessary in modern container shipments (Fig. 5). 


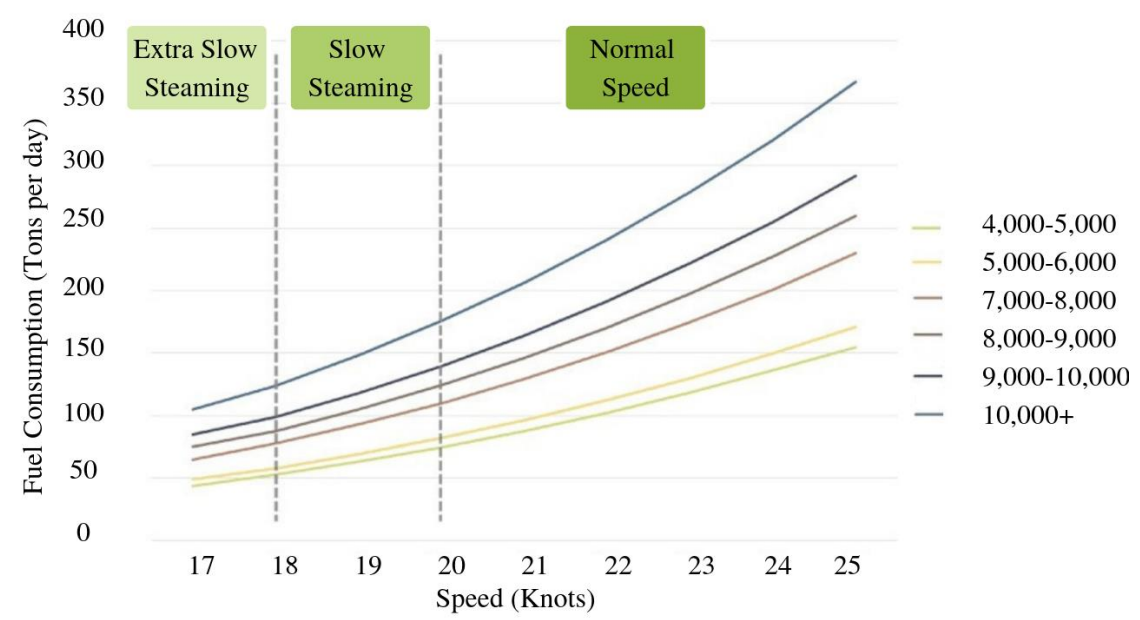

Fig. 4. Fuel consumption depending on the speed

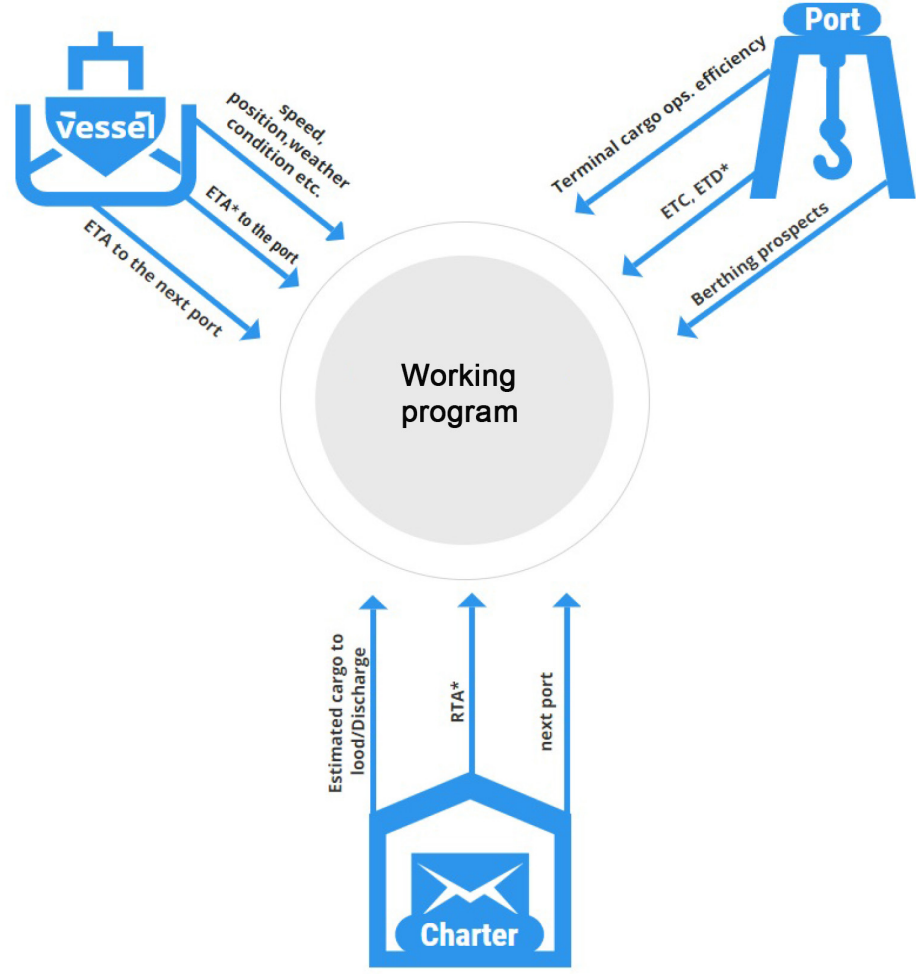

Fig. 5. Proposed scheme: *ETA - Estimated time of arrival, *ETC - Estimated time of completion, *ETD - Estimated time of departure, *RTA - Required time of arrival

\section{Conclusions}

After analyzing the situation in the modern container fleet market, it is possible to note a significant increase in fuel consumption associated with the following factors:

1. Significant increase in container fleet.

2. Increase deadweight of container fleet.

3. Increase in the average speed of container ships (in excess of $20 \mathrm{knots}$ ).

4. Inefficient use of energy resources due to the lack of a working conceptual feedback scheme.

Considering the problem of the influence of feedback on energy efficiency in the container fleet, one can note the main factors that ships face daily in practice: 
1. Inefficient use of high speeds.

2. Inefficient fuel costs.

3. Ship downtime.

4. Additional expenses of the shipowner.

The proposed scheme of principal relationships should not only increase the effectiveness of feedback between all participants in the process, but also increase the competitiveness of the ports themselves, which in turn will improve the quality of cargo transportation as a whole. Reduction of waste of fuel leads to increased energy efficiency and reduced emissions of harmful substances into the atmosphere in the segment of the container fleet. The shipper will have real information about the situation in the port, its productivity, and the prospects of setting it up at the berth at its appointed time. Based on this information, the shipper or charter will be able to use the ship more efficiently, avoiding unnecessary downtime and delays.

The introduction of the proposed scheme at the initial stages of development should take place at small container terminals with a small traffic flow. In the future, it can be applied to larger terminals with a higher traffic flow. At the initial stages of the implementation of the proposed scheme, difficulties may arise in attracting and motivating port services in providing up-to-date information about the situation in the port. But in the future, this information will help to identify shortcomings in the work of the port and eliminate them, which in turn will increase the competitiveness of the port itself.

Further study of the problem of inefficient feedback should improve energy efficiency, reduce emissions of harmful substances into the atmosphere, reduce the cost of shipowners, as well as improve the quality of sea freight as a whole.

\section{References}

[1] Sheydina, O. (2012). Okhrana okruzhayushhey sredy i energosberezhenie. Zeleneet. Available at: http://zeleneet.com/energosberezhenie-i-okruzhayushhaya-sreda/1397/

[2] Shipping emissions $17 \%$ of global $\mathrm{CO}_{2}$, making it the elephant in the climate negotiations room (2015). Available at: https://www.transportenvironment.org/press/shipping-emissions-17-global-co2-making-it-elephant-climate-negotiations-room

[3] Transparency International kritikuet rabotu IMO (2018). Rabotnik morya. Available at: http:// seafarers.com.ua/transparency-international-criticizes-imo/14626/

[4] Vladimirov, S. A. (2016). The global transport and logistics system: main areas of development. Regional'naya ekonomika i energetika, 2 (46). Available at: https://eee-region.ru/article/4602/

[5] Obzor morskogo transporta (2016). Organizatsiya ob»edinennykh natsiy. Geneva, 118. Available at: http://unctad.org/en/PublicationsLibrary/rmt2016_ru.pdf

[6] Just-in-time. Upravlenie proizvodstvom. Available at: http://www.up-pro.ru/encyclopedia/justin-time.html

[7] Öztürk, E. (2013). Operational Measures For Energy Efficiency In Shipping. Journal of ETA Maritime Science, 1 (2), 65-72. Available at: https://www.journalagent.com/jems/pdfs/JEMS_1_2_65_72.pdf

[8] Losiewicz, Z., Kaminski W. (2014). Practical Application of Ship Energy Efficiency Management Plan. Logistyka-Nauka, 3.

[9] The economics of slow steaming (2014). Seatrade Maritime News. Available at: http://www. seatrade-maritime.com/news/americas/the-economics-of-slow-steaming.html

[10] From management to operation in energy efficiency. International Maritime Organization. Available at: http://www.imo.org/en/OurWork/Environment/PollutionPrevention/AirPollution/Documents/ Air \%20pollution/M3 \%20TTT \%20course \%20Posters \%20finall.pdf

[11] Olmer, N., Comer, B., Roy, B., Mao, X., Rutherford, D. (2017). Greenhouse gas emissions from global shipping, 2013-2015. ICCT. Available at: https://www.theicct.org/sites/default/files/publications/Global-shipping-GHG-emissions-2013-2015_ICCT-Report_17102017_vF.pdf

[12] Johnson, H., Styhre, L. (2015). Increased energy efficiency in short sea shipping through decreased time in port. Transportation Research Part A: Policy and Practice, 71, 167-178. doi: http://doi.org/ 10.1016/j.tra.2014.11.008 